\title{
ALYTAUS MIESTO ARCHITEKTŪRA PRIEŠKARIU
}

\author{
Algimantas Mačiulis \\ Architektūros katedra, Vilniaus dailès akademija, \\ Maironio g. 6, 01124 Vilnius, Lietuva \\ El.paštasalgmaciulis@yahoo.com
}

Iteikta 20100329

\begin{abstract}
Santrauka. Straipsnyje aptariama Alytaus miesto architektūra prieškariu, istorinės aplinkybės, kai miestas, pradèjęs kurtis dešiniajame Nemuno krante, menkai plètojosi (I-as Alytus), o miesto branduolys, jo centras susiformavo upès kairiajame krante (II-as Alytus). Prieškariu II-me Alytuje šalia senamiesčio kūrèsi nauji rajonai - Naujamiestis, Kurortas. 1930-1940 m. - Alytaus augimo dešimtmetis, miestas plètėsi ir vystėsi kaip vasarvietè. Pažymėtina Alytaus apskrities ir miesto vyriausiojo inžinieriaus, architekto Vytauto Trečioko veikla, jo prieškariu projektuoti visuomeniniai ir privatūs gyvenamieji namai, tarp jų moderni Alytaus pradinė mokykla Nr. 4 Birutès g. 26.
\end{abstract}

Reikšminiai žodžiai: miesto planinẻ erdvinẻ sistema, mišri plano struktūra, miesto įvaizdis, miesto ir gamtos ryšys.

\section{Ivadas}

Nagrinëjant Alytaus miesto architektūrą prieškariu, tikslinga nors trumpai pateikti miesto urbanistinę raidą, šiek tiek istorijos faktų. Alytaus miestelis dokumentuose paminetas $1387 \mathrm{~m}$. Miestas pradžioje kūrèsi dešiniajame Nemuno krante (I-as Alytus). Čia ties santaka su Alytupiu ant vadinamojo Vienuolyno kalno piliakalnyje stovejo medinè pilis (XIV a. antroji pusé - XV a. pradžia). $1524 \mathrm{~m}$. pastatyta pirmoji bažnyčia, pradžioje buvusios vos kelios gatvès. Nuo $\mathrm{XV}$ a. pab. miestas pradejo plisti ir kairiajame Nemuno krante (II-as Alytus). XVI a. pirmoje pusejje pradeda formuotis miesto planiné erdviné sistema, miesto plano struktūra igauna netaisyklingą formą. Kuriasi keli senojo miesto centrai: I-me Alytuje - išplatintos gatvès pavidalo aikštė su senąja bažnyčia, kurios vietoje vèliau $1818 \mathrm{~m}$. pastatyta vèlyvojo klasicizmo mūrinè Šv. Liudviko bažnyčia (1931 m. pagal architekto Vaclovo Michnevičiaus projektą atlikta rekonstrukcija); II-me Alytuje - trikampė aikštė ir medinė Šv. Angelų Sargų bažnyčia, pastatyta senosios bažnyčios vietoje 1830 m. (išplèsta 1905 m.). XVI a. pagausèjo amatininkų, pagyvejjo prekyba. $1581 \mathrm{~m}$. miestas gavo
Magdeburgo teises. 1589 m. Alytus tapo ekonomijos miestu. $1595 \mathrm{~m}$. veike parapinè mokykla.

XVII a. miestą naikino gaisrai, ypač nukentejo per Šiaurès karą. XVII a. Alytus pradèjo atsigauti. Nuo $1795 \mathrm{~m}$. I-as Alytus priklause Rusijos imperijai, o II-as Alytus, esantis Suvalkų pusèje - 1795-1807 m. i̇ejo ị Prūsijos karalystės provinciją, Naująją Rytų Prūsiją. 1807-1815 m. visas miestas priklause Varšuvos kunigaikštystei, o 1815-1915 m. Lenkijos karalystei, buvusiai Rusijos imperijos sudètyje, jos autonominiam vienetui. $1812 \mathrm{~m}$. Alytų nusiaubė Napoleono prancūzų kariuomene. XIX a. antroje pusèje Alytus neteko miesto teisių, buvo paverstas Rusijos imperijos trečios eilès tvirtove. $1834 \mathrm{~m}$. issteigta pirmoji Alytaus ligoninè. Per Alytų nutiesti plentai ị Kalvariją, Daugus, geležinkelis $\mathfrak{i}$ Varéną ir Suvalkus. 1898 m. pastatytos kareivinės (Miškinis 2001).

Susiklosčius istorinėms aplinkybèms, Alytus pradejęs kurtis dešiniajame Nemuno krante, menkai plètojosi ir miesto branduolys, jo centras susiformavo kairiajame upès krante, dabartiniame II-me Alytuje, architektūriniu bei urbanistiniu požiūriu vertingiausioje miesto dalyje (1 pav.). 


\section{Alytus XX a. pradžioje}

Prieškariu Alytuje gyveno apie 10 tūkstančiu gyventoju (palyginimui: $1886 \mathrm{~m}$. - 926 gyventojai, $1897 \mathrm{~m}$. 3445 (iš jų I-me Alytuje - 1435, II-me Alytuje - 2010), 1923 m. - 6322, 1931 m. - 7124, 1940 m. - 9207, 1974 m. - 40 200, 2001 m. - 72300 gyventoju), tai buvo nedidelis miestas, labiau primenantis kurortą, skoningai tvarkomas. Kurortinio tipo gyvenvietei kurtis įtakos turejo puikios gamtinès sąlygos. Alytus asocijuojasi su ji supančiais gamtos vaizdais: pušynais, Nemunu, jo tapybiškais krantais. Nemunas miesto akivaizdoje daro didelę kilpą, gaubdamas Vizgirio mišką. Čia galima pajusti tiesiogini gamtos ryšs̆i, gamtos artumą: Vizgirio miškas iš pietų pusès natūraliai nusidriekia iki pat miesto centro, pastatai skęsta pušyne, žalumoje ir mieste gyvenantieji žmonès jaučia natūralios gamtos artumą.

1915 m. Alytus tapo apskrities miestu, 1918-1919 m. atgavo miesto teises. Pirmojo pasaulinio karo metu veikè nedidelè ligoniné, po karo - apskrities ligoninè. 1919 m. ìsteigta pirmoji lietuviška mokykla, išaugusi i Alytaus gimnaziją. 1918 m. gruodžio mèn. ị Alytų atkeltas Lietuvos kariuomenès pirmasis pulkas, kuris

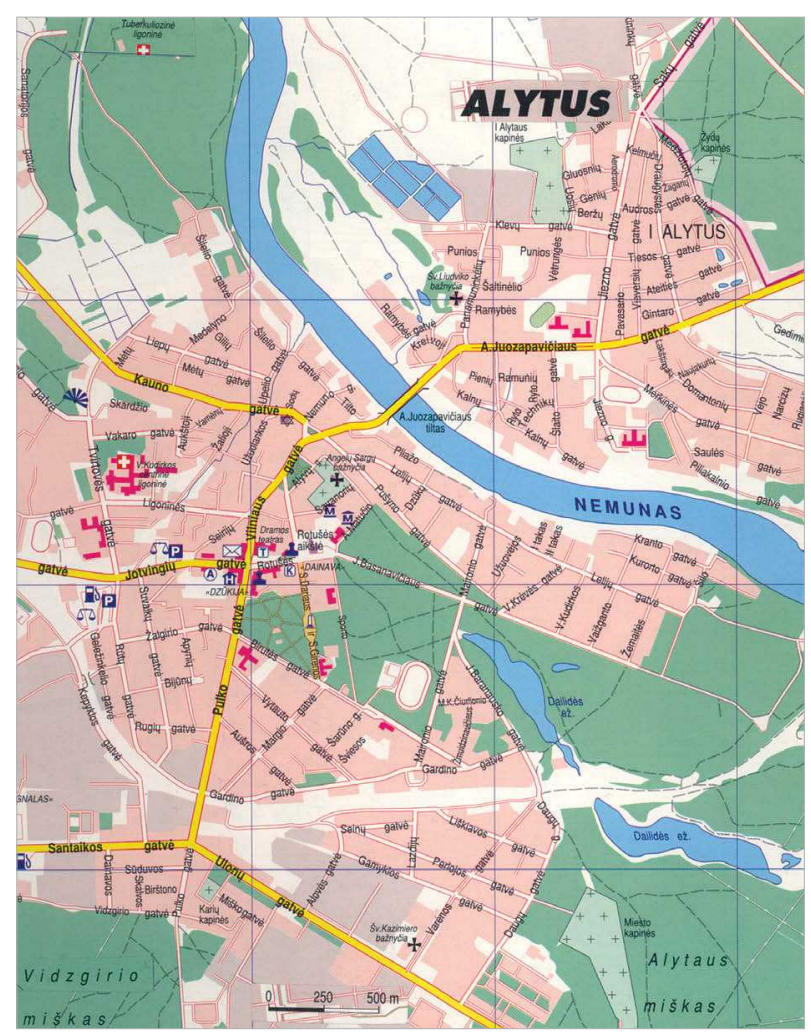

1 pav. Alytaus miesto planas (esama padetis)

Fig. 1. Plan of Alytus (current situation)
1919 m. vasario 12-15 d. kovėsi su bolševikais. Vasario $13 \mathrm{~d}$. ant tilto žuvo Lietuvos kariuomenès pulko vadas Antanas Juozapavičius. $1926 \mathrm{~m}$. ̣̇ Alytų atkeltas antrasis ulonų pulkas.

Nepriklausomybès metais Alytus garsėjo miškuparku miesto centre, ịkurtu 1927 m. Pirmąji ąžuolą 1927 m. pasodino Kipras Petrauskas. Parke įrengtas moderniu architektūrinių formų fontanas su rozariumu. Šalia pušų auga naujai pasodinti ąžuoliukai, akacijos, alèjas apšviesdavo originalūs žibintai. Miesto sode sekmadieniais estradoje ar pavėsinejje grodavo dūdų orkestras.

Šalia miesto sodo S. Dariaus ir S. Girèno g. 1928 m. vasario $16 \mathrm{~d}$. pastatytas Laisvès paminklas, kurị sukūrè skulptorius Antanas Aleksandravičius (1885-1970). Pjedestalo apatinè dalis, primenanti Gedimino stulpus, turèjo 4 nišas bareljefams. Pagrindinëje aukštoje paminklo dalyje dominavo per visą aukštị kardo atvaizdas. Paminklą vainikavo Nikès statula - trimituojantis angelas su sparnais. Dalis aikštès buvo išgrịsta neịprastomis medžio trinkelëmis - tai suteikè aikštei originalumo, intymumo. Po karo, 1948 m. paminklas nugriautas, aikštėje palaidoti rusų kareiviai ir naujai pastatyti du obeliskai (juos projektavo piešimo mokytojas Ipolitas Kiaunè). Atgavus valstybingumą, $1991 \mathrm{~m}$. Laisvès paminklas atstatytas (skulptorius Jonas Meškelevičius, architektas Algirdas Mainelis) (2 pav.).

Netoli paminklo ir aikštės S. Dariaus ir S. Girèno g. 27 stovi senoji lietuviškoji gimnazija, vienaukštis medinis pastatas, statytas 1924-1925 m. iš senų kareivinių sienojų, dar vadinamų Arklidèmis (buvusiose kareivinèse Pirmojo pasaulinio karo metu čia buvo irengtos arklides) (3 pav.). Be lietuviškosios gimnazijos, nuo $1927 \mathrm{~m}$. mieste pradejo veikti miškininkystès mokykla, 1929 m. - žemesnioji žemès ūkio mokykla. Mieste kūrèsi pramonè: 1928 m. ikurtas žemès ūkio padargu fabrikas „Ukmašina“, 1930 m. - daržoviu ir vaisių fabrikas, 1931 m. - aliejaus spaudykla, 1936 m. terpentino ir kanifolijos fabrikas.

Senamiestyje vyravo didelè turgaus aikštès erdvè (1989 m. turgaus aikšteje pastatyta naujoji rotušè; architektas Saulius Juškys). Turgaus aikštèje (dabartinė Rotušès aikštè), kuri buvo grịsta akmenimis, prieš karą vykdavo dideli turgūs. Antrojo pasaulinio karo metu dalis aikštę supančių namų buvo sugriauta ir aikštė neteko turèjusio vientiso architektūrinio vaizdo. Pokario metais ją pradèta atstatinèti atsitiktiniais pastatais, negalvojant apie kompozicinę visumą. Neapgalvotose vietose, neịvertinant Basanavičiaus gatvès svarbos, jungties su senąja Turgaus aikšte, buvo pastatytas 


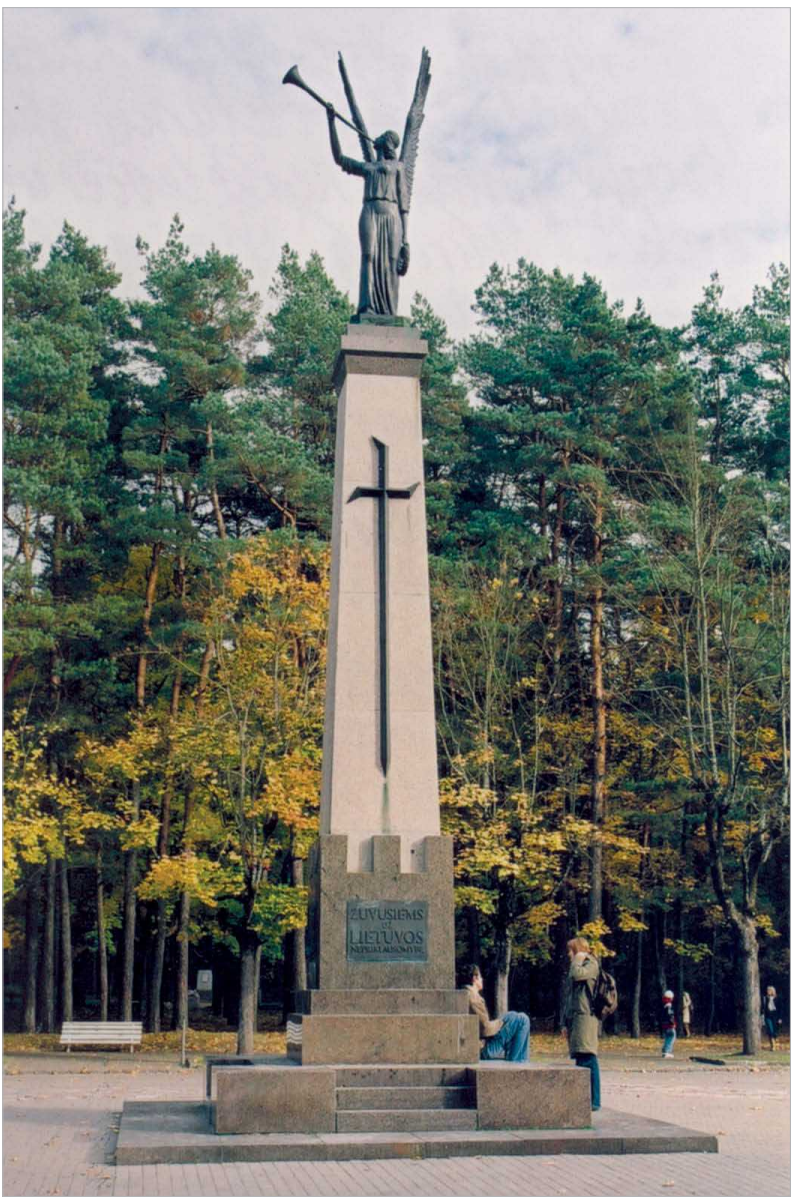

2 pav. Laisvès paminklas, pastatytas 1928 m., skulptorius Antanas Aleksandravičius. Nugriautas 1948 m., atkurtas 1991 m. (atkūrè skulptorius Jonas Meškelevičius, archit. Algirdas Mainelis)

Fig. 2. Monument "Freedom" (1928). Sculptor Antanas Aleksandravičius. Demolished in 1948, restored in 1991 (sculptor Jonas Meškelevičius, arch. Algirdas Mainelis)

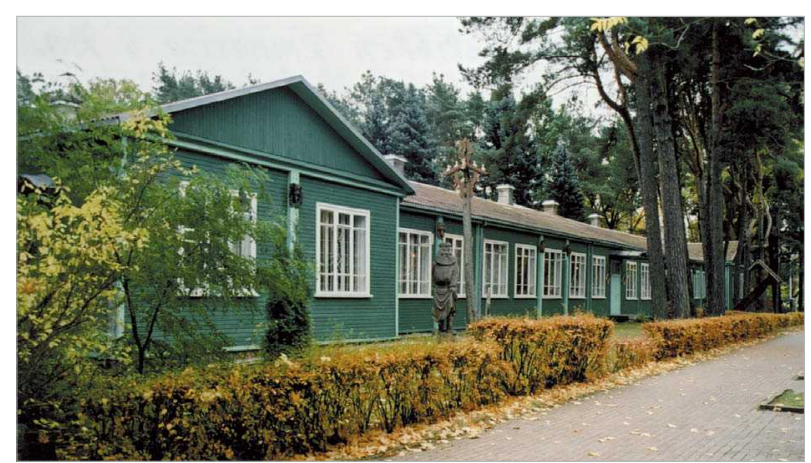

3 pav. Senoji lietuviškoji gimnazija S. Dariaus ir S. Girèno g. 27, pastatyta 1924-1925 m.

Fig. 3. Old Lithuanian gymnasium in S. Darius and S. Girènas str. 27 (1924-1925)
„Nemuno“ restoranas, kino teatras ir kt. Menkaverčiais pastatais, daugiausia privačiais gyvenamaisiais namais po karo užstatyta ir pagrindinè miesto magistrale Pulko gatvè.

Prieškariu II-me Alytuje šalia senamiesčio kūrèsi nauji rajonai: Naujamiestis, Kurortas, kurių gatvès buvo taisyklingo plano, miestas igavo mišrią plano struktūrą.

\section{0-1940 m. - Alytaus augimo dešimtmetis, klestėjimo metas}

Nepriklausomybès metais Alytus toliau plètėsi, miestas ypač gražèjo 1930-1940 m.

Alytuje, iškirtus dalị pušyno, buvo pastatytas stadionas. Jo statybą iniciavo žymus kūno kultūros specialistas Karolis Dineika (1898-1980), dirbęs Alytuje 1929-1934 m. Stadiono tribūnas, vartus, medžio lentelèmis išklotą krepšinio aikštelę suprojektavo architektas Feliksas Bielinskis (1904-1986, jis 1932-1936 m. projektavo stadioną ne tik Alytuje, bet ir Ukmergeje, Kaune, Marijampoleje). Alytaus stadione išugdyta žymių krepšininkų (vienas jų Antanas Kudzys, Lietuvos krepšinio rinktinès narys, vèliau akademikas, profesorius). Miestas turèjo pajègią krepšinio rinktinę, todèl neatsitiktinai 1939 m. po Europos krepšinio pirmenybių Lietuvos krepšinio rinktinè Alytaus stadione žaidè parodomąsias rungtynes su miesto komanda.

Šalia miesto parko stovi buvę Antano Juozapavičiaus vardo šaulių namai, dar vadinti kurhauzu (dabar kultūros namai), kurie pagal architekto Adolfo Lukošaičio (1906-1993) projektą buvo pastatyti 1938 m. (4 pav.). Juos derètų išsaugoti nepakeistus (Mačiulis 1991).

$1936 \mathrm{~m}$. buvo paskelbtas viešas konkursas tiltui per Nemuną Alytuje. Jị laimèjo inžinierius Anatolijus Rozenbliumas (1902-1973), pasižymèjęs kaip Kauno apskrities savivaldybės rūmų (1932), Tyrimų laboratorijos (1933), karininkų ramovès (1934) pastatų konstrukcijų inžinierius, Kauno sporto halès autorius (1938). Alytaus tiltas - tai vienas gražiausių ir moderniausių gelžbetoninių tiltų nepriklausomoje Lietuvoje. Apie naują tiltą ir jo kūrejus tuomet rašè spauda: „1938 m. gruodžio $15 \mathrm{~d}$. Alytuje iškilmingai atidarytas naujas gelžbetoninis karininko Juozapavičiaus vardo tiltas per Nemuną. Tiltą atidarè ministeris pirmininkas ir finansų ministeris J. Tūbelis. Naujasis tiltas yra $195 \mathrm{~m}$ ilgio, $9 \mathrm{~m}$ pločio ir $20 \mathrm{~m}$ aukščio nuo žemiausio vandens horizonto. Pagal darbų planą tiltas turëjo būti pastatytas per du statybos sezonus, t. y. per dvejus metus. Tačiau tiltą pavyko pastatyti per trumpesnị laiką. Paties tilto statyba kaštavo 900000 litų, žemès darbai, aplinkos tvarkymas - $200000 \mathrm{Lt}$, žemès nusavinimas, trobesių 


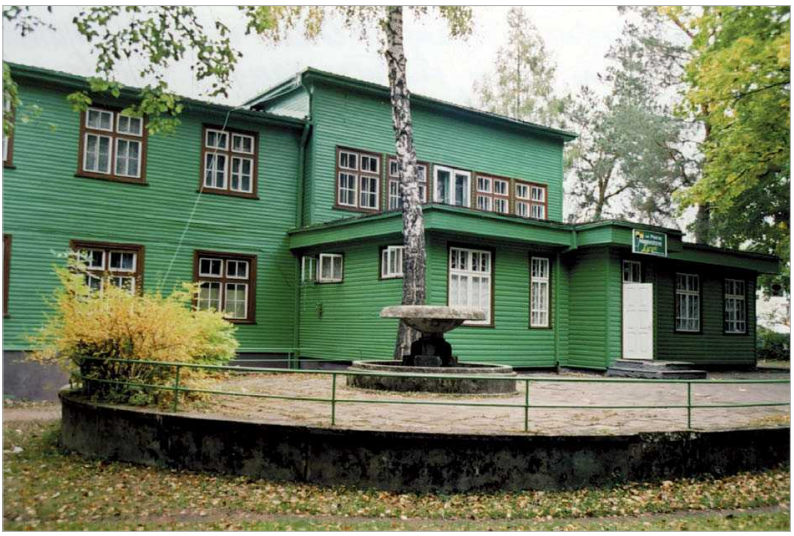

4 pav. Antano Juozapavičiaus vardo šaulių namai, kurhauzas (dabar kultūros namai), statyti 1938 m., archit. Adolfas Lukošaitis

Fig. 4. Shooter's House of Antanas Juozapavičius, kurhaus (now House of Culture (1938). Arch. Adolfas Lukošaitis

nukèlimas - 70000 Lt. Iš viso 1170000 Lt. <...> Alytaus tiltas žymus mūsų inžinerijos kūrinys, ekonominès mūsų krašto pažangos paminklas. <...> Tiltą state žinoma rangovų Ilgovskių firma" (Nakas 1997). Tiltui bareljefus sukūrè žymus skulptorius Juozas Zikaras (1884-1944), po karo atstatytam tiltui pagal originalo gipsines kopijas buvo nulieti bareljefai, kuriuos atliko dailininkas Vytautas Ledas (1991). Antrojo pasaulinio karo metu vokiečiai tiltą susprogdino (po karo sugriautas tiltas su nuslinkusiu ị vandenị sovietiniu tanku ilgai riogsojo). Tiltas buvo atstatytas, tačiau be modernių žibintų, elegantiškos formos turèklų ir kt.

Aprašomuoju laikotarpiu (1930-1940) toliau buvo intensyviai tvarkomas miesto centras, pastatyta nauju pastatų: 80 vietų ligoninè (čia dirbo žymus chirurgas Stasys Kudirka), tuberkuliozinè ligoninè-sanatorija, miesto savivaldybė, mokytojų seminarija, veikè du kino teatrai, keli restoranai, statomi privatūs gyvenamieji namai ir kt.

\section{Vytautas Trečiokas - Alytaus apskrities ir miesto vyriausiasis inžinierius, architektas}

Nepriklausomos Lietuvos Vyriausybė 1921 m. įsteigé Vyriausiąją statybos inspekciją, kuri svarste visus svarbiausius miestų ir miestelių naujų pastatų projektus. 1927 m. susirūpinta miestų architektūrine, estetine būkle: Lietuvos statybos įstatais leista griauti blogos būklès pastatus ar jų dalis. $1932 \mathrm{~m}$. nurodyta visiems miestams ir daugeliui miestelių parengti mūro staty- bos zonų schemas, apribota medinių pastatų statyba, miesto centrinèse dalyse, ypač centrinèse aikštèse, leista statyti tik mūrinius pastatus (spaudoje skelbtas šūkis „Už mūrinę Lietuvą!“). Pagal 1931 m. Savivaldybių i̊statymą apskrities miesto teises gavo dešimt miestų (Alytus, Biržai, Kaunas, Kèdainiai, Marijampolè, Panevėžys, Šiauliai, Telšiai, Ukmergè, Vilkaviškis). Apskrityse buvo ịsteigtos vyriausiųjų inžinierių (architektų) pareigybès.

1935 m. kovo mèn. pabaigoje Alytaus apskrities bei miesto vyriausiuoju inžinieriumi buvo paskirtas jaunas inžinierius Viktoras Ražaitis (1907-1991), neseniai baigęs aukštuosius mokslus Belgijoje, Lježo universitete (1928-1934). V. Ražaitis ilgai Alytuje neužsibuvo, vos pusmetị, suprojektavo Alytaus lentpjūvę, kurios savininkas Dominykas Dundzys buvo grižęes iš JAV (jis miesto centre pasistatydino kelis gyvenamuosius namus, kurie karo metu sudegé; sovietams nacionalizavus lentpjūvę, buvęs savininkas čia dirbo paprastu darbininku).

Išvykus V. Ražaičiui į Kauną, nuo 1935 m. Alytaus apskrities ir miesto vyriausiuoju inžinieriumi pradejo dirbti dabar mažai kam žinomas architektas Vytautas Trečiokas. V. Trečiokas gimė $1912 \mathrm{~m}$. spalio $9 \mathrm{~d}$. Biržuose, buvo šeštas daugiavaikeje šeimoje. 1930 m. baigè Biržų gimnaziją. 1930-1933 m. studijavo architektūrą Paryžiuje, Ecole des Travaux et Batiment universitete, 1935 m. baigè Kauno Vytauto Didžiojo universitetą. $1944 \mathrm{~m}$. emigravo ị Vokietiją, $1949 \mathrm{~m}$. atvyko ị Kanadą, dirbo architektūros firmoje Hully Que (1950-1955), nuo 1955 m. - Kanados viešųjų darbų ministerijoje Otavoje. Mirè Kanadoje (Lietuvių enciklopedija 1964).

V. Trečiokas, įvertinęs Alytaus gamtinę aplinką, siekè suteikti miestui kurorto ịvaizdị. Architektas Naujamiestyje (tarp Parko g. ir geležinkelio) suprojektavo jaukias gatveles su bulvarais (Aušros, Margio, Vytauto gatvès), šis kvartalas ir šiandien gali būti pavyzdžiu privačių namų naujųjų rajonų projektuotojams (5 pav.). Profesionaliai suplanuotas ir vadinamasis Kurorto rajonas (tarp Lelijų ir J. Basanavičiaus bei jas kertančių V. Krèvès, V. Kudirkos, T. Vaižganto ir Žemaitès gatvių). Čia privačias vilas gaubia pušynai, šalia esantis miškas organiškai susilieja su urbanizuota aplinka.

Be urbanistinių darbų, V. Trečiokas suprojektavo keletą vilų (pvz., Gydy tojo privatus namas Birutès g. 22). Architektas pats sau statėsi namą Šarūno g. 11, tačiau prasidèjus karo veiksmams, nespèjo užbaigti fasadų apdailos, sutvarkyti aplinkos, įrengti šalia namo van- 
dens baseinèlio (dabar šis pastatas renovuotas, šiek tiek pakeistas eksterjeras).

V. Trečiokas suprojektavo miesto pirtị šalia naujojo tilto per Nemuną, Tilto g. Architektas prisidejo kuriant naujojo tilto architektūrines detales (žibintus, turèklus). Pagal jo projektą pastatyta Santaikos bažnyčia Kriokialaukyje, Alytaus apskr.

Tačiau V. Trečioko reikšmingiausias kūrinys moderni Alytaus pradinè mokykla Nr. 4, esanti Birutès g. 26, pastatyta $1937 \mathrm{~m}$. (vèliau berniuku gimnazija) (6 pav.). Mokyklos fasadai buvo apdailinti gelsvo atspalvio tinku, tarpulangiai - tamsiai rudos spalvos, stogas - raudonų čerpių (dabar dengtas šiferiu). Eksterjere neịprastai atrodè pagrindinio įejimo tam-

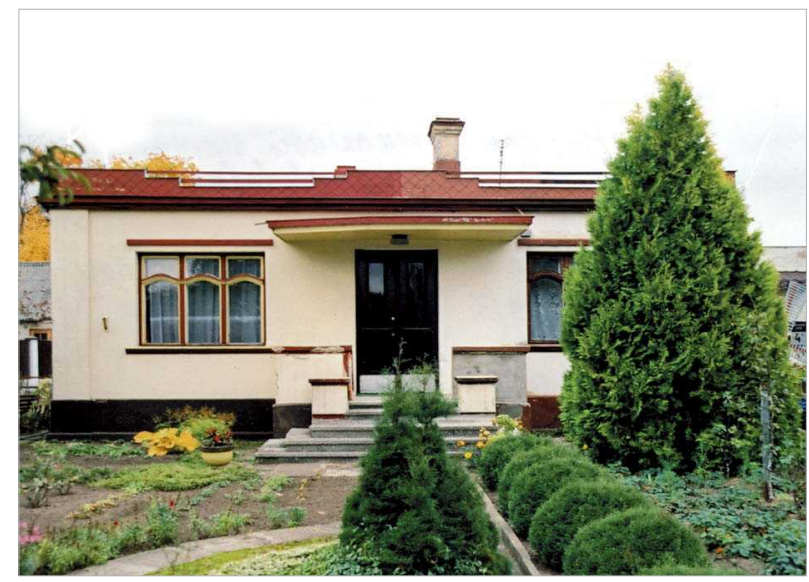

5 pav. Privatus gyvenamasis namas Naujamiestyje, Maironio g., statytas prieškariu

Fig. 5. Private dwelling house in new town, Maironis str., built before the War

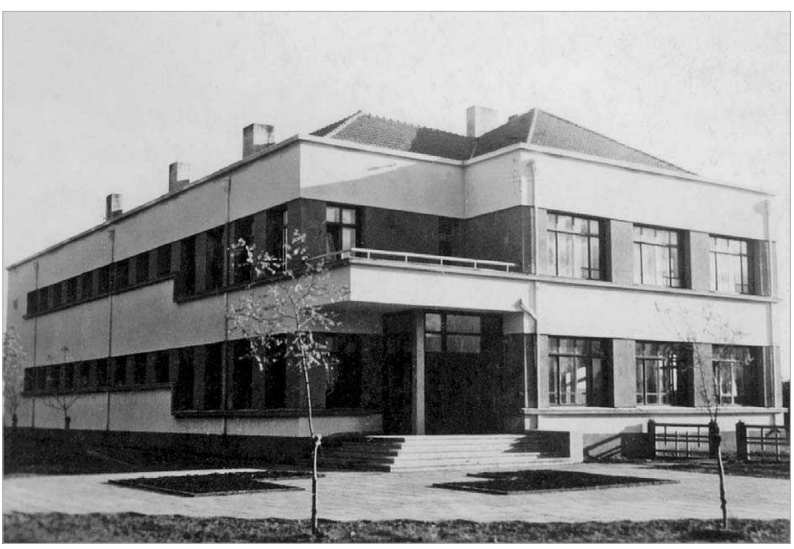

6 pav. Alytaus pradinè mokykla Nr. 4 Birutès g. 26, pastatyta 1937 m., archit. Vytautas Trečiokas (1939 m. nuotrauka)

Fig. 6. Elementary School No 4 of Alytus, Birutès str. 26, (1937) arch. Vytautas Trečiokas (picture of 1939) būras (neišliko). Mokyklos interjero įranga (vandens šaltinèliai bei atviros drabužių kabyklos koridoriuose, langų apkaustai ir kt.) buvo įsigyta Vokietijoje. $1938 \mathrm{~m}$. pavasarị naujoje mokykloje ịvyko dailininko Antano Žmuidzinavičiaus tapybos paroda, dalyvavo pats dailininkas, padovanojo vieną savo paveikslų, kuris buvo pakabintas aktų saleje. Dabar mokyklos pastatas puikiai suremontuotas, čia ịsikūrè Alytaus senamiesčio pradinè mokykla. Balti fasadai dvelkia modernia funkcionalizmo, Bauhauzo dvasia (Mačiulis 2008) (7 pav.).

\section{Išvados}

1. Per kelis šimtmečius Alytuje susiformavo mišri plano sistema: senamiestyje - netaisyklinga, o naujesnejje miesto dalyje - taisyklinga miesto planinè erdvinè struktūra.

2. Susiklosčius istorinèms aplinkybèms, miestas, pradejęs kurtis dešiniajame Nemuno krante, plètojosi menkai (I Alytus), miesto branduolys, jo centras susiformavo upès kairiajame krante (II Alytus), architektūriniu bei urbanistiniu požiūriu vertingiausioje miesto dalyje.

3. Miesto plètrai buvo reikšmingi 1930-1940 m., kai intensyviai tvarkomas miesto centras, pastatyta nemažai visuomeninių pastatų (miesto ligoninè, tuberkuliozinè ligoninè-sanatorija, miesto savivaldybè, mokytojų seminarija ir kt.), taip pat naujas gelžbetoninis tiltas per Nemuną.

4. Alytaus apskrities ir miesto vyriausiasis inžinierius, architektas Vytautas Trečiokas, dirbęs 19351944 m., siekè suteikti miestui kurorto, vasarvietès ịvaizdị.



7 pav. Alytaus senamiesčio pradinè mokykla dabar (po rekonstrukcijos)

Fig. 7. Elementary School of Alytus old town (after reconstruction) 


\section{Literatūra}

Lietuvių enciklopedija. 1964. Trečiokas Vytautas, t. 31. JAV. Bostonas, 431.

Mačiulis, A. 1991. Alytus - trijų miestų konglomeratas, Statyba ir architektūra 2: 12-14.

Mačiulis, A. 2008. Permainų metai, Architekto užrašai. Vilnius: Vilniaus dailès akademijos leidykla, 20-22.

Miškinis, A. 2001. Alytus, iš Visuotine lietuvių enciklopedija, t. $1: 351-353$.

Nakas, A. 1997. Architektas inžinierius Vytautas LandsbergisŽemkalnis ir jo darbų konstruktoriai. Vilnius: Technika. 67 p.

\section{PRE-WAR ARCHITECTURE OF ALYTUS TOWN}

\section{A. Mačiulis}

Abstract. During a couple of hundred years, a mixed-plan system has been formed in Alytus: an irregular one in the old town and exact and rational in the new town parts, based on a regular street network, correct plan and spatial structure. Historical factors determined the town's development: on the right bank of the Nemunas river the development was slow (Alytus I), and the center of the town, formed on the left bank of the Nemunas river (Alytus II), from the urban point of view, was the most valuable part of the town. The period 1930-1940 was extremely important for the town's development: central areas were arranged, quite a number of public buildings were built (town hospital, tuberculosis sanatorium, town municipality, seminary, etc.), a reinforced concrete bridge over Nebulas. In 1935-1944 Vytautas Trečiokas, the chief architect and designing engineer of Alytus district, tried to make Alytus look like a holiday resort and designed a modern elementary school.

Keywords: town plan and spatial structure, mixed-plan system, town image, harmony between town and nature.

\section{ALGIMANTAS MAČIULIS}

Doctor of the Humanities (architecture), Professor, Department of Architecture, Vilnius Academy of Fine Arts, Maironio 6, 01124 Vilnius, Lithuania. E-mail:algmaciulis@yahoo.com

Teaching: architectural composition, the history of modern architecture, critical analysis of architecture. Membership: member of the LAS (Lithuanian Union of Architects). Publications: author of 120 scientific publications. Projects: author of 25 projects of architectural design. Research interest: modern processes in architecture, interaction between architecture and art. 